\title{
PRE-PAPILLARY CYST DEVELOPED FROM REMNANTS OF THE HYALOID ARTERY*
}

\author{
BY \\ J. FrançOIS \\ From the Department of Ophthalmology, University of Ghent, Belgium.
}

THE duct of Cloquet is a tubular area which traverses the eyeball in its anterior-posterior axis from the optic disk to the posterior pole of the lens. It develops at the expense of the central or original vitreous, which is progressively absorbed from the third month of intra-uterine life, during the formation of the definitive vitreous.

In the human foetus the duct of Cloquet exists from the sixth month and generally disappears shortly after birth. It contains the hyaloid artery, the ramifications of which form a vascular sheath embracing the posterior lens capsule. In young children, and even in adults, remnants either of the duct of Cloquet or of the hyaloid artery can sometimes be seen.

The duct of Cloquet may persist in the shape of a membrane, which is inserted into some part of the optic disk, covers the emergence of the vessels and ends in the vitreous, either in the form of a point or club, or in the form of membranous expansions. Some types of hyaloid remnants are easily recognized. The following are some examples :

(1) A white tubercle, bright and quite small found on the emergence of the central retinal artery like a bud on the bough of a fruit-tree.

(2) An arterial handle leaving the optic disk and projecting into the vitreous.

(3) A mobile cord or dark filament, arising from the optic disk and ending by a free extremity in the vitreous.

These prepapillary formations should not be mistaken for hyaline drusen at the optic disk or for the epipapillary membrane. The latter covers the whole of the optic disk and is attached to the vessels where they emerge. It may be opaque or transparent and somewhat ill-defined, and may encroach slightly upon. the neighbouring retina.

Very exceptionally one can find prepapillary cystic formations, probably related to remnants of the hyaloid artery. The cases of Durst (1909), Risley (1896), Koller (1900), Paton (1910), Levitt and Lloyd (1939), Yudkin (1926), Hilgartner (1940), Levine (1932), Purtscher (1936) and Mérigot de Treigny and Subileau (1927) are 
well known. These cysts develop before or shortly after birth. They may resemble a tumour in size. Rounded and greyish, they are situated on the optic disk and project into the vitreous. They may have a stalk of variable length. The presence of blood has been detected and occasionally they have been mistaken for cysticercus cysts (Liebreich, 1854 ; Vassaux, 1883).

They develop from the vascular system proper of the hyaloid artery or from the glial tissue which surrounds it, or from the mesodermal tissue which penetrates the vitreous together with the artery, or from the potential space between the artery and its glial mantle.

According to Durst, the following characteristics distinguish a prepapillary or congenital papillary cyst from an acquired one :

(1) The existence of associated congenital anomalies.

(2) The absence of signs of old or recent inflammation.

(3) The absence of vessels.

(4) The presence of amblyopia and squint.

\section{Case Reports}

The following descriptions of prepapillary cysts, taken from the literature, are of interest.

1. Levitt and Lloyd (1939).-A well-defined and rounded cyst-formation, 3 D.D. in diameter and greyish-white in colour, covers part of the optic disk and of the neighbouring retina. In its lower half the retinal vessels run distinctly on the surface, whilst in the upper half, they are veiled, being situated behind the cyst. There are no pigment flecks, no exudates, no haemorrhages. Vision and visual field are normal.

2. Yudkin (1926).- At the upper nasal part of the optic disk, a whitish rounded mass, 2 dioptres in height and $1 \frac{1}{2}$ D.D. in breadth. This well defined but lightly pigmented mass is crossed by a fairly important vessel and a few other tiny vessels can be observed.

3. Hilgartner (1940).- In a 12-year-old child, on the level of the optic disk, there is a white, avascular mass, 5 dioptres in height and $\frac{1}{3}$ D.D. in breadth. After a lapse of 5 years no change occurred in this mass. V.A. less than $1 / 10$.

4. Levine (1932).- In a 14-year-old girl, a cystic avascular mass situated on the nasal margin of the optic disk, 5 dioptres in height.

5. Risley (1896).- The upper half of the optic disk is covered by a grey cystic tumour, transparent, avascular and $2 \mathrm{~mm}$. in height. Under this tumour there is a hyaloid remnant, but there is apparently no anatomical relation between the two formations.

6. Durst (1909).--Astride the temporal margin of the optic disk is a cyst, rounded and grey and formed by a transparent and thin tissue. At the summit of the tumour, which is surrounded by a dim and dusty area of the vitreous, a few thin vessels are seen.

7. Purtscher (1936).- - On the level of the upper-temporal quadrant of the optic disk, there is a rounded tumour, greyish-red in colour and $1 \mathrm{~mm}$. in height. On its surface is a network of capillaries, some of which penetrate the mass. Simultaneously with the veinous retinal pulse, the tumour turns alternately red and pink, and when the eyeball is compressed it becomes quite pale and can be distinguished from the optic disc with difficulty.

8. Mérigot de Treigny and Subileau (1927). - The temporal half of the optic disk is hidden behind a bright whitish formation, of conical shape and irregular base. Being 3 DD. in breadth, it encroaches upon the neighbouring retina. Homogeneous and avascular, it has frayed edges. The eye is convergent, hypermetropic by 6 dioptres and amblyopic. 


\section{Personal Observation}

A girl, aged two and a half years, brought to me on October 28, 1943, had developed, some months previously, a right convergent concomitant squint associated with bilateral hypermetropia. (R.E.: + 3.50 D., L.E.: + 2.50 D.)

Right eye.-Excluding the squint, no other lesion was apparent except a small whitish and fibrous streak, situated at the posterior pole of the lens. Visual acuity was less than 1/10 (amblyopia ex anopsia).

Left eye.-(See Figure). In front of the optic disk there was a voluminous bilobular cyst, 3 D.D. $\times 2$ D.D., greyish in colour,

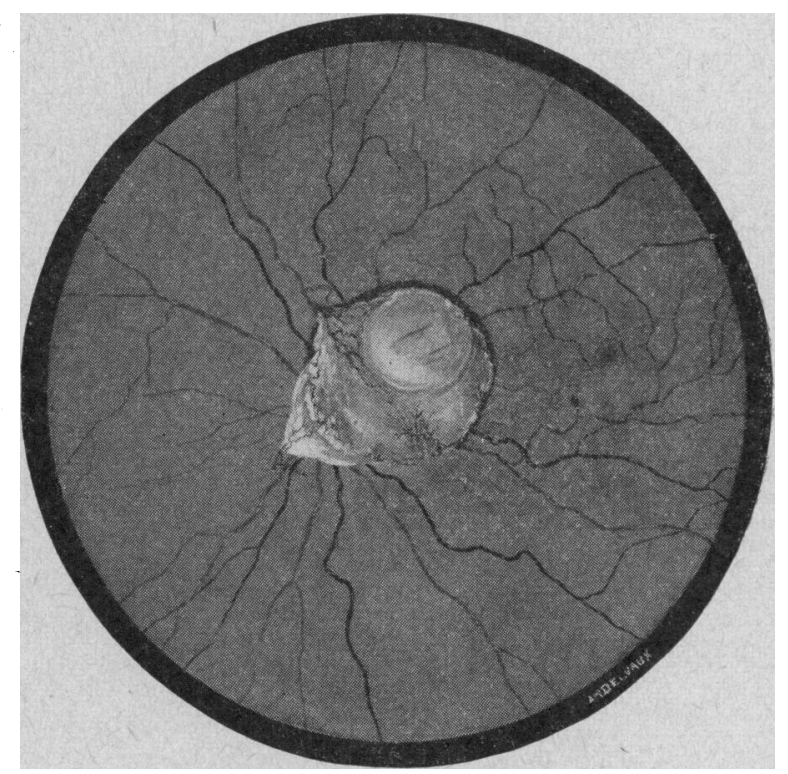

FigurE.--Prepapillary cyst in left eye..

but transparent. Adherent to the disk and about $3 \mathrm{~mm}$. in height, the cyst was slightly mobile. Two vascular bundles emerged seemingly from the posterior face above and beneath it and joined each other on the anterior surface of the cyst with the production of two unequal lobes. On the lateral temporal face of the upperanterior lobe a small, rather short, vascular bundle was observed. On the nasal side of the optic disk there was a flat triangular formation, fibrous in appearance and rather vascular. There was no other ocular anomaly to report except for a remnant of the hyaloid artery at the posterior pole of the lens. 
During the past six years the cyst has undergone no change either in structure or in volume. It can therefore be considered as congenital. The prepapillary situation and the integrity of the visual functions suggest that the optic fibres were not involved and that it was developed from remnants of the hyaloid artery.

In January, 1946, I observed below and within the macular region a few small punctiform haemorrhages (three or four). In October, 1947, these haemorrhages had increased in number, but in November, 1948, they had completely disappeared. In February, 1949, there was a new haemorrhage, at exactly the same site. (See Figure). I think I can ascribe these retinal haemorrhages to a mechanical irritation, brought about by the movements and the friction of the cyst.

It should be noticed that the visual acuity of the left eye stayed at 10/10 throughout and that it was the right eye which was convergent and amblyopic, although anatomically the better fashioned. This shows that the criteria of Durst for the differentiation of acquired and congenital prepapillary cysts do not always hold.

Finally it should be noticed that but for the ocular anomalies the child was normal and there was nothing relevant to report concerning her personal or family history.

\section{REFERENCES}

Condes, F. C. (1940). Arch. Ophthal., Chicago, 23, 1063.

DEBECK, D. (1890). Amer. Ophthal. Monogr., 3, 1.

DURST (1909). Thesis, Leipzig.

DVorak, L. (1932) Klin. Mbl. Augenheilk., 88, 643.

Hilgartier, H. L. (1940). Amer. J. Ophthal., 23, 186.

Koller, C. (1900). Trans. Amer. ophthal. Soc., 9, 380.

Levine, J. (1932). Arch. Ophthal., Chicago, 8, 209.

Levite, J. M., and Lloyd, R. I. (1939). Amer. J. Ophthal., 22, 760.

LiEBREICH, R. (1855). Graefes Arch. Ophthal., 1, abt. 2, p. 343.

Merigot de Treigny, P. and Subileau, J. (1927). Bull. Soc. Ophtal., Paris, $39,513$.

Parsons, J. H. (1906). "The Pathology of the Eye", Hodder and Stoughton, London. 3, 851 .

Paton, L. (1910). Trans. ophthal. Soc. U.K., 30, 150.

Purtscher, E. (1936). Z. Augenheilk., 88, 217.

Randall, B. A. (1888). Trans. Amer. Ophthal. Soc., 5, 117.

RISLEY, S. D. (1896). Ibid., 7, 606.

Rockliffe, W. C. (1887). Trans. ophthal. Soc. U.K., 7, 226.

Vassaux G. (1883). Arch. Ophtal., Paris, 3, 502.

YUdKIx, A. M. (1926). Arch. Ophthal., Chicago, 55, 364. 